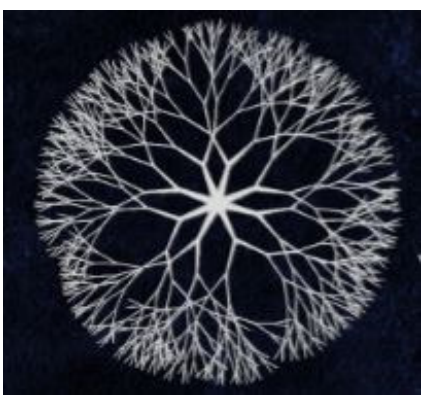

ARTIGOS - ARTICLES

\title{
Uma questão inconveniente: a ideia de progresso como conceito fundador e estruturante da cientificidade da história da arte
}

\author{
Danielle Rodrigues Amaro \\ Doutoranda em História Social - FFLCH - USP \\ danielle.amaro@gmail.com
}

Recebido em 23/04/2017. Aprovado em 29/06/2017.

Como citar este artigo: Amaro, D. R. "Uma questão inconveniente: a ideia de progresso como conceito fundador e estruturante da cientificidade da história da arte”. Khronos, Revista de História da Ciência, nº 4, pp. 132 - 152.2017. Disponível em <http://revistas.usp.br/khronos >. Acesso em dd/mm/aaaa.

Resumo: A partir do problema levantado pelo historiador da arte Alberto Cipiniuk sobre o que observa como uma indefinição acerca da compreensão e, por consequência, da abordagem do fenômeno artístico no contexto acadêmico brasileiro, pretende-se debater os conflitos existentes na história da arte entre as perspectivas internalista e externalista, estética e histórica. Como consequência do tema abordado e de forma a desenvolver parte dessas questões, trazemos para o centro do debate a tese defendida pela historiadora Olga Hazan a respeito do papel estruturante da ideia de progresso para a história da arte.

Palavras-chave: História da arte, Historiografia da arte, Internalismo, Externalismo, Progresso.

\section{An inconvenient question: the idea of progress as a founding and structural concept of the scientific character of art history}

\begin{abstract}
From issues raised by the art historian Alberto Cipiniuk about what he noticed as an uncertainty about the understanding and, consequently, the approach to the artistic phenomenon in the Brazilian academic context, it is intended to discuss the existing conflicts in art history between internalist and externalist, aesthetics and historical conceptions. As a consequence of the theme and in order to develop some questions, we bring to the center of the debate the thesis defended by the art historian Olga Hazan about the structuring role of the idea of progress in art history.
\end{abstract}

Keywords: Art History, Art Historiography, Internalist and Externalist Concepts, Progress. 
No XXIV Colóquio do Comitê Brasileiro de História da Arte (UFMG, Belo Horizonte/MG, 2004) o historiador da arte Alberto Cipiniuk apresentou comunicação intitulada "A silenciosa querela entre os partidários do entendimento da arte como categoria estética e os simpatizantes da arte como categoria histórica". O artigo dela resultante, publicado nos anais do encontro, é iniciado com uma contextualização do seu lugar de discurso, do recorte a partir do qual observava e argumentava naquele momento1. Partia de uma "observação empírica" de seu "trabalho como professor universitário de história da arte". No entanto, se suas reflexões emergiam de sua "vivência acadêmica no Instituto de Artes da UERJ", o autor optava, entretanto, por não enfatizar a particularização de tal análise, preocupando-se assim em remeter "a discussão para um plano mais geral” por supor tratar-se de uma questão que, em sua opinião, parecia "existir de forma disseminada no mundo acadêmico"2.

Cipiniuk narra os conflitos que permearam as discussões ocorridas no final da década de 1990, sobre a reforma curricular da licenciatura em Educação Artística com habilitação em História da Arte oferecida pela UERJ, então sob a responsabilidade do Departamento de Educação Artística da Faculdade de Educação. Faz referência a um problema particular: "a quebra dos pré-requisitos nas disciplinas de história da arte”, de forma a oferecer aos alunos a possiblidade de dispensá-los "dos períodos artísticos mais antigos para que pudessem cursar os períodos mais recentes".

A existência de pré-requisitos para o curso da série de disciplinas intituladas de modo geral "História da Arte" e "História da Arte no Brasil" é ainda hoje uma questão fundamental na estruturação dos currículos das graduações história da arte no país e Cipiniuk esclarece sua posição sobre o tema da querela: "naquela ocasião eu defendi a quebra de todos os pré-requisitos, pois considerava que o aluno deveria ter capacidade de saber, por exemplo, se era mais proveitoso para ele estudar a arte do século XVIII antes de se dedicar ao século XIX”. Relata ainda que propôs a introdução, no ato da matrícula, de um procedimento o qual denominava “orientação acadêmica”, a fim de que "os alunos pudessem realizar escolhas mais ponderadas sobre os conteúdos programáticos, e não apenas seguissem os períodos históricos dos mais antigos para os mais recentes".

Cipiniuk justifica que isso responderia a uma demanda prática: "o fluxo dos alunos durante o curso", pois "quando o aluno não podia se inscrever em uma disciplina por conta de um pré-requisito ele deveria esperar um ano para fazê-lo". Havia, no entanto, entre os professores do grupo uma voz dissidente, que defendia a permanência dos pré-requisitos, argumentando que sua ausência "desarticularia todo o ensino histórico da arte". O controverso colega pressupunha a existência de "conhecimentos propedêuticos nos períodos anteriores que impossibilitava que os alunos passassem para os períodos mais recentes desconsiderando os acontecimentos do passado". Cipiniuk assim relata o andamento da contenda: "a discussão foi intensa e esse nosso colega afirmava que a ausência desse seguimento, dessa conexão, era um imenso "misunderstanding" [mal-entendido, equívoco]. [...] A quebra dos pré-requisitos foi aprovada, mas havia no ar matéria ou assunto para debates. Naquela ocasião pensávamos em discutir essas questões em um simpósio acadêmico, mas isso nunca se realizou”3.

${ }^{1}$ CIPINIUK, Alberto. A silenciosa querela entre os partidários do entendimento da arte como categoria estética e os simpatizantes da arte como categoria histórica. In: CAMPOS, Adalgisa Arantes; VIEIRA, Ivone Luzia; RIBEIRO, Marília Andrés; HUCHET, Stéphane (org.). Anais do XXIV Colóquio do Comitê Brasileiro de História da Arte. Belo Horizonte. Belo Horizonte: Comitê Brasileiro de História da Arte, 2005. pp.1-4. Disponível em:

$<$ http://www.cbha.art.br/coloquios/2004/anais/textos/03_alberto_cipiniuk.pdf>. Acesso em: 05 de janeiro de 2016.

2 CIPINIUK, 2005, op. cit., p.1.

${ }^{3}$ CIPINIUK, 2005, op. cit., p.1. 
De acordo com a análise de Cipiniuk, o debate acerca da quebra dos pré-requisitos curriculares evocava necessariamente uma outra questão, sobre a qual lamentava a ausência de uma "discussão metódica ou ordenada": trata-se da definição do "tipo de análise" a ser empregada para "o estudo do fenômeno artístico na história da humanidade". Ressalta que o grupo não tinha dúvidas tanto sobre a vinculação da produção artística "ao contexto social e ao seu período histórico", como também havia uma unânime posição "contra as análises positivistas ou mecanicistas da arte, especialmente no que se tratava da transformação dos estilos, do surgimento de novas expressões artísticas, de suas conexões com o seu próprio tempo, e também com a arte do passado". No entanto, ao lado das certezas elencadas, havia um grande silêncio sobre que metodologias deveriam ser aplicadas "para o estudo da arte nos diferentes períodos da história e, sobretudo, como um período se relaciona com outro".

O professor registra ainda a ausência de uma discussão a respeito do "tipo de análise" também nos anos anteriores", entre 1980 e 1998 (ou seja, praticamente durante as duas décadas de funcionamento do curso para a UERJ desde sua transferência da Escola de Artes Visuais do Parque Lage). Sobre esse período, afirma que

O procedimento teórico mais comum na UERJ e empregado pelos professores de história da arte no Departamento de Educação Artística era a apresentação das obras seguindo a linha do tempo, do passado para o presente, de forma causal, como uma hora segue outra, e que as análises estéticas eram quase que unânimes em relação às apreciações formalistas. Resumia-se a sujeição das pinturas renascentistas à composição triangular e das pinturas barrocas à linha diagonal ou a curva espiral ascendente. Quanto à passagem dos estilos, a relação entre o velho e o novo, a arte do passado e a do presente, a tônica era o emprego das categorias evolucionárias de Wölfflin, da forma clássica para a anticlássica e assim por diante. ${ }^{5}$

Cipiniuk chega a lembrar de um ocorrido no período anterior à reforma

Certa vez, insistindo em debater com uma colega sobre as posições de Lévi-Strauss sobre a ideia de progresso na história, assunto que ele desenvolvera de forma conclusiva em "Raça e história" e as de Hauser em "História Social da Literatura e da Arte", ouvi, para encerrar o assunto, que aquilo, a discussão entre o movimento sincrônico (estruturalista) e o movimento diacrônico (marxista) - se haveria uma "evolução" histórica, ou como os acontecimentos se desenrolavam segundo o viés da luta de classes e do tempo - era uma "briga de comadres. ${ }^{6}$

Mais adiante, conta ainda que, ao narrar o episódio anterior a um dos novos colegas, contratados em meados na década de 1990, teve como resposta que sua "posição historicista, frente ao formalismo dos outros colegas, era ultrapassada, que não cabia mais perdermos tempo nessa contenda". O autor lança os seguintes questionamentos: "afinal, por qual motivo existe esse silêncio? Por qual motivo a discussão não se pauta concretamente naquilo que é preciso? Por qual motivo ela flutua insegura e imprecisa, reforçando uma indeterminação? "7.

${ }^{4}$ CIPINIUK, 2005, op. cit., p.2.

5 CIPINIUK, 2005, op. cit., p.2.

${ }^{6}$ CIPINIUK, 2005, op. cit., p.2.

7 CIPINIUK, 2005, op. cit., p.4. 
Cipiniuk relaciona o silêncio ao discutir tais questões com a renovação do quadro docente ocorrido em meados da década de 1990, quando "no campo das atividades práticas, os antigos professores que tinham tido suas formações na Escola de Belas Artes do Rio de Janeiro foram integralmente substituídos por artistas de alguma projeção no campo da arte contemporânea". Sendo assim, se a renovação contribuiu para a criação de "uma atmosfera favorável para discussões e definição de um novo currículo e uma posição mais clara de como deveríamos nos comportar segundo os métodos de ensino de história da arte", tendo favorecido inclusive importantes avanços institucionais para os debates a respeito da produção artística e da história da arte, como a criação da Revista Concinnitas (1996) e inauguração do Instituto de Artes (2002); não foi acompanhado por um debate sistemático sobre as metodologias, o qual "foi acontecendo de forma indireta ou silenciosa". O professor afirma ter razões para acreditar que "esse debate silencioso seja ideológico", que se manifesta na "falta de posições claras entre um ou outro postulado" $"$. Assim argumenta

Entendemos que a aparente incapacidade de posicionamento no estudo do fenômeno artístico, especialmente o contemporâneo, se afirma como ideológica. $\mathrm{Na}$ verdade, nesse pequeno trabalho procuro enunciar algo que ainda é um pouco confuso para mim, pois me parece que meus colegas já têm uma posição teórica definida, mas não as expressam com clareza. Trata-se de algo que chamo de a lógica de Tancredi [personagem da obra literária "O Leopardo" de Giuseppe Tomasi di Lampedusa (1896-1957) ]: "é preciso que tudo mude para que tudo fique como está". Embora eu possa constatar que meus colegas compartilhem comigo a crença da articulação entre o campo fenomenal da arte com a vida social, se recusam a desvendar o resultado das suas análises calcadas em relações sociais ou tendências históricas. Não há, efetivamente, uma censura explícita. O que eu percebi, e que de certo modo me incomodou, foram caçoadas, cochichos seguidos de risos irônicos, que se traduziram na impressão de que havia uma acusação de determinismo, superficialidade ao viés historicista. Possivelmente eu estabelecia uma associação da linha historicista à vulgarização papalva da teoria marxista do reflexo. Poderia citar exemplos mais concretos dessas associações, mas este não é o objetivo desse trabalho. Ainda que possam afirmar que a arte não é um fato da cultura, como foi dito de forma explicita por um colega recentemente, recusando enquadramentos sociológicos, na prática constatam a evidência da influência externa à grandeza suprema da estética do objeto. Estranhamente lêem e citam Adorno e quase todos tiveram algum tipo de formação universitária no Departamento de História da Pontifícia Universidade Católica do Rio de Janeiro, isto é, em história social da cultura, lendo Norbert Elias e tantos outros que fazem essa aproximação. Dessa forma, evitando o contexto social, as análises historicistas, negando a parecença de uma forma artística com uma ideologia social, fazem-no às escondidas, plantam rosas no jardim de entrada, mas se lambuzam até os cotovelos chupando mangas no fundo do quintal. ${ }^{9}$

Cipiniuk usa como exemplo para as suas ponderações as formas dúbias de compreensão e uso do termo "arte contemporânea", que ora expressa uma categoria histórica, delimitando a produção realizada no tempo presente; ora uma categoria estética, delimitando uma forma específica de produzir arte. Logo, ao passo que delimita um recorte temporal, também aponta "um estilo, gênero ou maneira de fazer ou produzir a arte". Pode-se deduzir assim que nem toda "arte" produzida hoje é contemporânea, já que não depende apenas de

${ }^{8}$ CIPINIUK, 2005, op. cit., pp.2-3.

${ }^{9}$ CIPINIUK, 2005, op. cit., p.3. 
quando é produzida, mas da forma como os códigos são usados pelo sistema de arte: artista, instituições divulgadoras, crítica especializada, mercado, expectador, etc. E aí percebe-se um irônico paradoxo: ao mesmo tempo em que, na contemporaneidade temporal, há um consenso sobre as limitações do paradigma estilístico de narrativa, o termo também se define como um modo de produção, demarcando assim um certo estilo, ideia combatida pela contemporaneidade, entendida tanto no seu sentido temporal e quanto estilístico. Para Cipinuk, "a ambiguidade que se origina desse câmbio sistemático se traduz como falta de coragem de definir com clareza a que se refere o fenômeno estudado. Essa atitude não é teórica, mas ideológica"10.

Sobre a ambiguidade do termo "contemporâneo" aplicado à produção artística conforme é apresentado por Cipiniuk, o filósofo e crítico de arte estadunidense Arthur Coleman Danto defende, por exemplo, que não se trata simplesmente de um conceito temporal (arte "que está sendo feita agora"), tal como é também o caso do termo moderno (arte que foi feita "ainda há pouco"). Para Danto, só há sentido em discriminar, por exemplo, moderno e contemporâneo porque "a história da arte evoluiu internamente, a contemporânea passou a significar uma arte produzida dentro de certa estrutura de produção jamais antes vista em toda a história da arte creio eu"11.

Danto é leitor, comentador e devedor da filosofia hegeliana, que é uma referência fundamental para a compreensão dos percursos da produção artística ocidental e dos debates entorno dela nos últimos dois séculos, o que inclui necessariamente a fundação da história da arte como campo de pesquisa científica autônomo. Nesse sentido, penso ser importante retomar alguns de seus aspectos que julgo essenciais para os fins das análises que são aqui empreendidas. Me deterei particularmente em seus "Cursos de Estética".

Hegel inicia-os delimitando seu objeto de estudo e tão logo problematiza o próprio termo que os nomeia - estética -, o qual não considera "de todo adequado", pois seu uso não circunscreve apenas a apreciação da arte, mas designa "a ciência do sentido, da sensação". Mesmo não prosseguindo nesse debate, considera a nomeação "filosofia da arte" ou, mais especificamente, "filosofia da bela arte" como a mais precisa e adequada para tal ciência. Posta tal diferenciação, exclui, por conseguinte, o "belo natural". Hegel reconhece o exercício cotidiano de se atribuir o belo a céu, rio, flores, animais, seres humanos, mas argumenta que o "belo artístico" se sobrepõe ao "belo natural": "a beleza artística é a beleza nascida e renascida do espírito e, quanto mais o espírito e suas produções estão colocadas acima da natureza e seus fenômenos, tanto mais o belo artístico está acima da beleza da natureza"12.

A bela arte é, segundo a estética hegeliana, a arte "livre tanto em seus fins quanto em seus meios" (diferente da "servil", que cumpre papel de diversão e entretenimento, de adorno), cuja importância de sua tarefa coincide com a esfera da religião e da filosofia: "tornar-se apenas um modo de trazer à consciência e exprimir o divino, os interesses mais profundos da humanidade, as verdades mais abrangentes do espírito"13.

Os povos depositam nas obras de arte as suas intuições interiores e representações mais substanciais, sendo que para a compreensão da sabedoria e da religião a bela arte é muitas vezes a chave - para muitos povos inclusive a única. Esta determinação a arte possui em comum com a religião e a filosofia, mas de um modo peculiar, pois expõe sensivelmente

${ }^{10}$ CIPINIUK, 2005, op. cit., pp.3-4.

${ }^{11}$ DANTO [A], Arthur Coleman. Após o fim da arte: a arte contemporânea e os limites da história. Tradução de Saulo Krieger. $1^{a}$ edição. São Paulo: Odysseus Editora; EDUSP, 2006. p.12.

12 HEGEL [A], Georg Wilhelm Friedrich. Cursos de Estética I. Tradução de Marco Aurélio Werle. $2^{\mathrm{a}}$ edição. São Paulo: Edusp, 2001. pp.27-28.

${ }^{13}$ HEGEL [A], 2001, op. cit., p.32. 
o que é superior e assim o aproxima da maneira de aparecer da natureza, dos sentidos e da sensação. ${ }^{14}$

O caráter servil atribuído à arte não é para Hegel necessariamente um impeditivo para que ela seja tratada como objeto digno de "consideração científica", já que servir para outros fins também é algo que ocorre com o "pensamento". Em suas palavras, a própria ciência, por um lado, "pode ser empregada como entendimento servil para fins finitos e meios casuais e assim não adquire sua determinação a partir de si mesma, mas a partir de outros objetos e relações; por outro lado, ela também se liberta dessa servidão para se elevar à verdade numa autonomia livre, na qual ela se realiza independentemente apenas com seus próprios fins"15.

Para Hegel, a arte deve contribuir para a marcha do espírito na direção da autoconsciência. No entanto, esse lugar privilegiado conferido à arte não faz dela, "seja quanto ao conteúdo seja quanto à Forma, o modo mais alto e absoluto de tornar conscientes os verdadeiros interesses do espírito". E completa: “o pensamento e a reflexão sobrepujam a bela arte". Ao mesmo tempo em que reconhece que a produção artística é um estágio importante do desenvolvimento do pensamento, Hegel também avalia que, em sua época, a arte não proporcionaria a mesma "satisfação das necessidades espirituais que épocas e povos do passado nela procuravam e só nela encontraram" 16 . Isso pode ser melhor compreendido tendo em vista a relação estabelecida pelo filósofo entre Conteúdo, matéria e Forma na obra de arte. Hegel compreende o desenvolvimento da arte a partir de uma narrativa de adequação entre Conteúdo e Forma e organiza as formas de expressão artística de acordo com uma lógica de uso e depuração da matéria. Nas palavras do filósofo, as quais tornam evidentes sua concepção baseada em ciclos dialéticos:

Cada arte tem o seu tempo de florescimento de formação consumada como arte - e para ambos os lados um antes e um depois desta consumação. Pois os produtos do conjunto das artes são obras do espírito e, portanto, não estão imediatamente prontos no interior de seu domínio determinado tal como as configurações da natureza, mas são um começar, progredir, consumar e finalizar, um crescer, florescer e degenerar. ${ }^{17}$

Essa história é dividida pelo filósofo em três partes. A primeira é a Forma de arte simbólica. Hegel a considera como sendo o "estágio inicial da arte", "o início da arte", devendo ser assim "considerado como que apenas pré-arte". Encontrando seu maior desenvolvimento no Oriente Antigo (particularmente no Egito), "somente nos conduz depois de múltiplas transições, transformações e mediações para a autêntica efetividade do ideal enquanto Forma de arte clássica"18. Hegel ainda afirma que "a arte simbólica alcança sua efetividade mais adequada e sua maior aplicação na arquitetura"19.

A segunda é a Forma de arte clássica, na qual Conteúdo e Forma encontram um justo equilíbrio, uma adequação, cujo ápice de desenvolvimento revela-se na Grécia Antiga. É nela que também o belo, aspirado desde a simbólica, aparece: "a beleza clássica tem como o seu interior o significado livre, autônomo, ou seja, não um significado de qualquer coisa, mas o que

14 HEGEL [A], 2001, op. cit., p.32.

${ }^{15}$ HEGEL [A], 2001, op. cit., p.32.

${ }^{16}$ HEGEL [A], 2001, op. cit., pp.34-35.

17 HEGEL, Georg Wilhelm Friedrich. Cursos de Estética III. Tradução de Marco Aurélio Werle e Oliver Tolle. $1^{a}$ edição. São Paulo: Edusp, 2002. p.16.

18 HEGEL, Georg Wilhelm Friedrich. Cursos de Estética II. Tradução de Marco Aurélio Werle e Oliver Tolle. $1^{\mathrm{a}}$ edição. São Paulo: Edusp, 2000. p.23.

${ }^{19}$ HEGEL [A], 2001, op. cit., p.102. 
significa a si mesmo e, desse modo, também o que se interpreta a si mesmo"20. É na escultura que manifestará seu apogeu.

A terceira e última é a Forma de arte romântica, "algo mais elevado do que a bela aparição do espírito e sua forma sensível imediata, mesmo se esta também foi criada pelo espírito como adequada a ele". Funda-se no cristianismo, quando, "em vez da plástica multiplicidade de deuses, a arte conhece agora apenas um Deus, um espírito, uma autonomia absoluta" 21. Manifesta-se na pintura, na música e na poesia, a última ocupando um lugar privilegiado. Assim, resume Hegel as diferenciações e as transições entre essas três formas de arte:

Encontramos, no começo da arte, no Oriente, o espírito ainda não livre para si mesmo; ele procurava o que para ele era absoluto ainda no natural e, por isso, apreendeu o natural como divino em si mesmo. Mais adiante, a intuição da arte clássica expôs os deuses gregos enquanto indivíduos imperturbados, espiritualizados, mas igualmente de modo essencial ainda indivíduos afetados pela forma humana natural, enquanto acometidos de um momento afirmativo; e a arte romântica primeiramente aprofundou o espírito em sua própria interioridade, diante da qual a carne, a realidade exterior e a mundanidade em geral, embora o espiritual e o absoluto apenas tinham de aparecer neste elemento, estavam incialmente postas como nulidade, mas por fim souberam sempre mais e mais conquistar novamente para si validade de modo positivo. ${ }^{22}$

Hegel propõe então seu “sistema das artes particulares", um processo dialético que leva em conta as características materiais e espaciotemporais de cada uma das artes, sendo o progresso percebido pelo prescindir da matéria, que vai do mais pesado ao mais etéreo. Nessa escala, encontra-se em primeiro lugar a arquitetura; sucedida pela escultura; e, de forma a encerrar o ciclo, "uma última totalidade" que se divide em três: a pintura, a música e a poesia ${ }^{23}$. Assim, "a matéria inteiramente exterior, objetiva no mau sentido da palavra, dissipa-se por fim na sequência de estágios das artes particulares, no elemento subjetivo do som, o qual se subtrai da visibilidade e torna o interior perceptível apenas para o interior" ${ }^{24}$. Esse sistema deve ser lido em paralelo à forma como o filósofo escalona os cinco sentidos humanos de acordo com sua relação puramente teórica com os objetos: do menos ao mais, tato, paladar, olfato, visão e audição, sendo os dois últimos aqueles sentidos que, por excelência, "têm a capacidade [...] de serem órgãos para a apreensão de obras de arte" por estabelecerem "uma relação puramente teórica com os objetos" 25 . A partir disso torna-se compreensível "a conhecida divisão em artes plásticas, as quais elaboram o seu conteúdo visivelmente para a forma e cor objetivas exteriores, em segundo lugar em artes sonoras, a música, e em terceiro lugar na poesia, a qual, como arte discursiva, emprega o som meramente como signo, a fim de se voltar por meio dele ao interior da intuição, do sentimento e da representação espirituais"26.

Esses ciclos não são tão lineares como a sucinta descrição pode aparentar. Dentro de cada um desses três grandes ciclos (simbólico, clássico, romântico), há outros movimentos dialéticos internos ocorrendo. No entanto, não nos é possível e realmente não nos interessa tratar de forma tão detalhada a estética hegeliana. Por ora, consideramos que essas referências

${ }^{20}$ HEGEL, 2000, op. cit., p.157.

${ }^{21}$ HEGEL, 2000, op. cit., pp.252; 254.

22 HEGEL, 2000, op. cit., p.338.

23 HEGEL, 2002, op. cit., pp.25-29.

${ }^{24}$ HEGEL, Georg Wilhelm Friedrich. Cursos de Estética IV. Tradução de Marco Aurélio Werle e Oliver Tolle. $1^{a}$ edição. São Paulo: Edusp, 2004. p.14.

25 HEGEL, 2002, op. cit., pp.23-24.

${ }^{26}$ HEGEL, 2002, op. cit., p. 25. 
nos bastam já que apontam para algo que inclusive será evocado pela produção artística e historiográfica durante todo o século XX: a ideia de ciclos que se esgotam e são substituídos por outros mais adequados, em uma marcha em direção ao progresso. No entanto, se para Hegel o fazer arte deixaria de ter sentido em determinado estágio do movimento dialético em direção à autoconsciência, chegando assim ao seu fim para ceder lugar à filosofia, o tempo encarregou-se de mostrar que a arte e as suas narrativas alcançariam um certo ponto de autocrítica que a levariam para "além dos limites da história", expressão usada por Hegel e referenciada inúmeras vezes por Danto, particularmente em sua obra "Após o fim da arte: a arte contemporânea e os limites da história". Em uma das citações da expressão, Danto explica o contexto do uso crítico que faz do termo referenciando uma passagem particular de "A Filosofia da História", na qual Hegel descreve a África como parte "não-histórica" do mundo, na qual o espírito em marcha estaria em um estágio de subdesenvolvimento, sendo seu dever apresentá-la "apenas como no limiar da História do Mundo"27. Danto avalia assim que

\begin{abstract}
A visão de história de Hegel impõe que apenas certas regiões do mundo, e só em determinados momentos, eram verdadeiramente "mundo histórico", de modo que outras regiões, ou a mesma região em outros momentos, não eram parte realmente do que estava ocorrendo historicamente. Faço menção a isso porque as concepções de história da arte que pretendo contrastar com a minha definem, de modo semelhante, somente alguns tipos de arte como historicamente relevantes, e os demais como não estando presentes no momento "histórico mundial", não sendo por isso merecedores de real consideração. Essa arte - por exemplo, a arte primitiva, a arte popular, o artesanato - não é, como os adeptos dessas concepções comumente dizem, realmente arte, simplesmente porque, na frase de Hegel, reside "além dos limites da história". ${ }^{28}$
\end{abstract}

Para Danto, retomar o argumento de Hegel do esgotamento dialético da produção artística e, de forma crítica, "reivindicar que a arte chegou a um fim significa dizer que [...] nenhuma arte é historicamente mais verdadeira do que outra, nem em especial mais falsa. [...] Não pode mais haver nenhuma forma de arte determinada historicamente, todo resto sendo colocado além dos limites"29. Danto não se opõe à ideia de uma essência da arte, mas critica a forma como ela aparece tanto em Hegel e como é usada posteriormente por artistas, críticos e historiadores da arte. Em suas palavras

\begin{abstract}
O quadro é então o seguinte: existe um tipo de essência trans-histórica na arte, por toda a parte e sempre a mesma, mas que só se revela por meio da história. Até esse ponto, eu vejo como algo consistente. O que não considero válido é a identificação dessa essência com determinado estilo de arte [...] significando que a arte de qualquer outro estilo é falsa. Isso conduz a uma leitura ahistórica da história segundo a qual toda arte é essencialmente a mesma - toda arte, por exemplo, é essencialmente abstrata - tão logo despimos o disfarce, ou o acidente histórico que não pertence à história da 'arte enquanto arte"'.30
\end{abstract}

Por esse motivo e aproveitando o ensejo para retomar o argumento citado anteriormente sobre o entendimento da expressão "arte contemporânea" como uma categoria

27 DANTO [A], 2006, op. cit., p.29; HEGEL [B], Georg Wilhelm Friedrich. The Philosophy of History. Tradução de J. Sibree. Kitchener: Batoche Books, 2001. Disponível em: <http://www.efm.bris.ac.uk/het/hegel/history.pdf>. Acesso em: 25 de fevereiro de 2017. p.117.

${ }^{28}$ DANTO [A], 2006, op. cit., pp.29-30.

${ }^{29}$ DANTO [A], 2006, op. cit., p.31.

30 DANTO [A], 2006, op. cit., p.32. 
estilística, Danto prefere “chamá-la simplesmente por arte pós-histórica”, pois a "falta de uma unidade estilística, ou pelo menos do tipo de unidade estilística que pode ser alcançada à condição de critério e utilizada como base para o desenvolvimento de uma capacidade de reconhecimento" impossibilita assim qualquer tentativa de "direcionamento narrativo", algo que ainda caracterizava o modernismo ${ }^{31}$. Chamado por Danto também como "era dos manifestos", o modernismo "trouxe o que supunha ser filosofia ao centro da produção artística": "um manifesto distingue a arte que ele justifica como sendo a arte verdadeira e única, como se o movimento por ela expressado tivesse feito a descoberta filosófica do que a arte essencialmente é". No entanto, a produção pós-histórica viria demonstrar que "a verdadeira descoberta filosófica" é "que não existe uma arte mais verdadeira do que outra, bem como não há uma única forma que a arte necessariamente deva assumir: toda arte é igual e indiferentemente arte" 32 .

Assim, além de um presumível problema de definição do que é arte (afinal, sendo tudo permitido, por que nem tudo é aceito?), Danto pensa que a arte contemporânea ou pós-histórica é também marcada por uma "desordem informativa", um tipo de entropia e liberdade estética, não havendo mais qualquer "limite histórico". No entanto, ao mesmo tempo em que "tudo é permitido", torna-se "mais impositivo compreender a transição histórica da arte moderna para a pós-histórica"33

\begin{abstract}
O contemporâneo deixou de ser moderno a não ser no sentido do "mais recente", e o moderno passou a parecer cada vez mais um estilo que floresceu de aproximadamente 1880 até algum momento da década de 1960. Acho que se poderia mesmo dizer que alguma arte moderna continuava a ser produzida depois disso - uma arte que permanecia sob imperativos estilísticos do modernismo - mas aquela arte não seria realmente contemporânea, exceto, novamente, no sentido estritamente temporal do termo. Pois quando o perfil estilístico da arte moderna se revelou, ele o fazia porque a própria arte contemporânea revelava um perfil muito diferente do da arte moderna. ${ }^{34}$
\end{abstract}

$\mathrm{Na}$ fala de Danto, dois aspectos se ressaltam. Em primeiro lugar, apesar de defender um tipo de ruptura entre moderno e contemporâneo, isso não se dá de forma definitiva, mas estilos diferentes continuam coexistindo no mesmo recorte temporal. Logo, é possível pensar que há uma margem de contaminação, de indefinição entre uma forma e outra de fazer arte e que talvez as rupturas não sejam tão drásticas e definitivas como reclamavam os manifestos modernistas da primeira metade do século XX. Nas palavras de Danto: "a história não passa por mudanças abruptas nem freadas bruscas" 35 .

Em segundo lugar, ele demarca de forma muito precisa o início do contemporâneo na década de 1960, o que não é gratuito: toda a reflexão de Danto a respeito do que chamamos arte contemporânea pauta-se principalmente numa análise da produção artística pop dos Estados Unidos, mas detendo-se de forma particular às "Caixas Brillo" de Andy Warhol (Figura 1). Em "A transfiguração do lugar comum” (1981), Danto narra o impacto por ele vivenciado, primeiro, diante do quadro “O beijo" de Roy Lichtenstein (Figura 2) e, posteriormente, da obra de Warhol; que resultou na elaboração de seu primeiro ensaio sobre estética sob o título "O mundo da arte"36, cujo argumento norteador, "em consonância com o clima da hora, tinha um conteúdo

${ }^{31}$ DANTO [A], 2006, op. cit., p.15.

32 DANTO [A], 2006, op. cit., pp.34;38.

33 DANTO [A], 2006, op. cit., p.15.

${ }^{34}$ DANTO [A], 2006, op. cit., p.13.

${ }^{35}$ DANTO [A], 2006, op. cit., p.38.

36 Apresentado pela primeira vez no encontro anual da American Pbilosopbical Association, em 1964, o artigo

"The art world" foi traduzido e publicado no Brasil pela revista Artefilosofia, da Universidade Federal de 
político: como um objeto adquire o direito de participar, como obra, do mundo da arte? "37. Assim argumenta o filósofo em trecho do citado artigo:

O Sr. Andy Warhol, o artista pop, exibe fac-símiles de caixas de Brillo, em pilhas altas, em limpas prateleiras como no estoque do supermercado. [...] O custo dessas caixas chega a ser de $2 \times 10^{3}$ o das congêneres na vida real - um diferencial dificilmente atribuível a sua maior durabilidade. $\mathrm{Na}$ verdade, o pessoal da Brillo pode, mediante algum custo extra, fazer suas caixas de compensado, sem que elas se tornem obras de arte, e Warhol pode fazer as suas a partir do papel-cartão, sem que elas deixem de ser arte. Desse modo, podemos esquecer as questões relativas ao valor intrínseco e indagar por que o pessoal da Brillo não pode manufaturar arte e por que Andy Warhol não pode fazer nada senão obras de arte. [...] Esse homem é uma espécie de Midas, transformando tudo em que ele toca no ouro da pura arte? E o mundo todo, consistente de obras de arte latentes, esperando, como o pão e o vinho da realidade, para ser transfigurado, por meio de algum mistério obscuro, na carne e no sangue do sacramento? Não importa que a caixa de Brillo possa não ser boa - menos ainda grande - arte. O que chama a atenção é que ela seja arte de algum modo. Mas, se ela é, por que não o são as indiscerníveis caixas de Brillo que estão no depósito? Ou toda a distinção entre arte e realidade caiu por terra? [...] O que, afinal de contas, faz a diferença entre uma caixa de Brillo e uma obra de arte consistente de uma caixa de Brillo é uma certa teoria da arte. É a teoria que a recebe no mundo da arte e a impede de recair na condição do objeto real que ela é (num sentido de é diferente do da identificação artística). É claro que, sem a teoria, é improvável que alguém veja isso como arte e, a fim de vê-lo como parte do mundo da arte, a pessoa deve dominar uma boa dose de teoria artística, assim como uma quantia considerável da história da recente pintura nova-iorquina. Isso poderia não ter sido arte cinquenta anos atrás. [...] $\mathrm{O}$ mundo tem que estar pronto para certas coisas - o mundo da arte não menos do que o real..$^{38}$

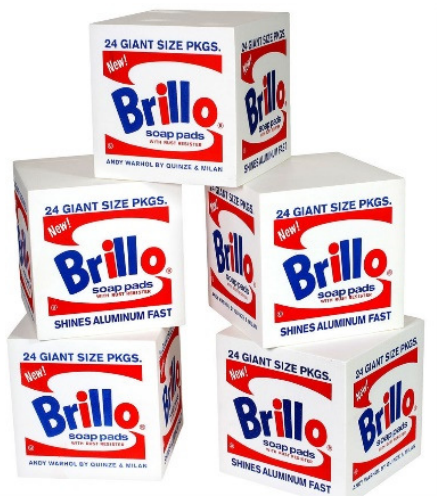

Figura 1. Andy Warhol (1928-1987). Caixas Brillo, 1964. Serigrafia e pintura sobre compensado. Fonte: The Andy Warhol Foundation for the Visual Arts.

Ouro Preto. Ver: DANTO [B], Arthur Coleman. O mundo da arte. In: Revista Artefilosofia. Tradução de Rodrigo Duarte. Ouro Preto: UFOP, $\mathrm{n}^{\circ} 1$, julho de 2006. pp.13-25. Disponível em: <https://moodle.ufsc.br/pluginfile.php/1560412/mod_resource/content/1/artefilosofia_01_01_mun do_arte_arthur_danto.pdf $>$. Acesso em: 06 de janeiro de 2016.

${ }^{37}$ DANTO, Arthur Coleman. A transfiguração do lugar-comum: uma filosofia da arte. Tradução de Vera

Pereira. $1^{a}$ edição. São Paulo: Cosac Naify, 2005. p.16.

${ }^{38}$ DANTO [B], 2006, op. cit., pp.21-22. 


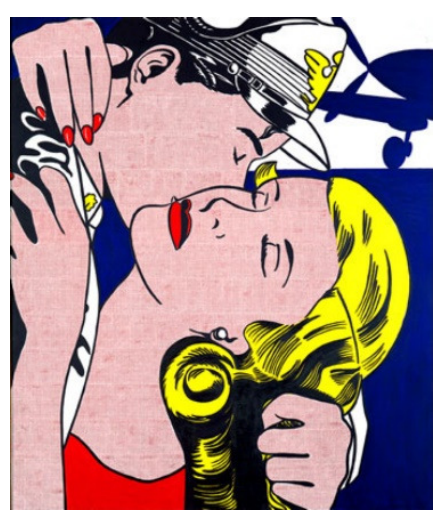

Figura 2. Roy Lichtenstein (1923-1997). O beijo, 1961. Óleo sobre tela. Fonte: Roy Lichtenstein Foundation.

Abro aqui um breve parêntese para uma contextualização necessária: como é descrito pelos próprios autores, os primeiros argumentos a respeito do "fim da arte" de Arthur Danto e do "fim da história da arte" do historiador da arte alemão Hans Belting foram publicados pela primeira vez na década de 1980, sem qualquer tipo de sincronização intencional.

Em 1984, Danto publicou o ensaio "O fim da arte" no livro "A morte da arte", editado por Berel Lang ${ }^{39}$, sendo esse o seu primeiro de outros ensaios sobre o fim da arte que escreveria nos anos seguintes. Um ano antes, em 1983, Belting já havia publicado a obra "O fim da história da arte? "40. Uma década depois, o historiador revisou sua tese e a republicou sem o ponto de interrogação, cuja supressão foi justificada pelo fato de que aquilo que se apresentara anteriormente para ele como uma pergunta, tornou-se certeza com o passar dos anos e a aproximação da virada do século XX. Contudo, Belting salienta: "não se trata de algumas palavras de ordem convincentes, mas de juízos e observações que precisam de espaço onde se desenvolver e que, além disso, são tão provisórias como, afinal, é provisório tudo o que hoje vem à baila" ${ }^{\prime 1}$. Da mesma forma, após aproximadamente uma década da declaração original, Danto publicou "Após o fim da arte: a arte contemporânea e os limites da história", um tratamento expandido da temática do primeiro ensaio, como uma tentativa de atualizar a ideia, formulada outrora ainda de modo "um tanto vago", sobre o fim da arte. Sobre o sincronismo de percepção e abordagem do tema, Danto justificará anos depois que tal simultaneidade deveuse à percepção vívida que ambos tiveram de que alguma mudança histórica ocorrera nas condições de produção das artes visuais ${ }^{42}$.

A partir de pontos de observação diferentes e complementares - o primeiro, da filosofia; o segundo, da história da arte -, ambos chegam a mesma conclusão: o anúncio do "fim" não significa que tudo acabou, mas torna imprescindível repensar as narrativas com as quais representamos a produção artística. Ainda com relação ao artigo "O mundo da arte", o próprio Danto afirma que ele "serviu de base para a Teoria Institucional da Arte e tornou-se um texto de leitura obrigatória não só na estética, como também na sociologia da arte"43. A teoria tem relação com o problema da definição da obra de arte e é retomada, por exemplo, pelo

${ }^{39}$ LANG, Berel (ed.). The Death of Art. Nova York: Haven, 1984.

40 BELTING, Hans. Das Ende der Kunstgeschichte? $1^{\mathrm{a}}$ ed. Berlim: Deutscher Kunstverlag, 1983.

${ }^{41}$ BELTING, Hans. O fim da bistória da arte: uma revisão dez anos depois. Tradução de Rodnei Nascimento. $1^{a}$ edição. São Paulo: Cosac Naify, 2006. p.9.

42 DANTO [A], 2006, op. cit., pp.3-4.

${ }^{43}$ DANTO, 2005, op. cit., p.17. 
antropólogo Alfred Gell em artigo ${ }^{44}$ no qual discute as formas de distinção dos objetos artísticos em relação aos objetos cotidianos, ordinários.

Finalmente, retomando as questões lançadas por Cipiniuk, uma das controvérsias por ele apontada como pouco discutida, por exemplo, é a questão da relação entre progresso, produção artística e história da arte: "como a história progride"; "se ela progride, como se dá essa progressão"; "se existe um escalonamento no tempo, uma continuidade, ou uma modificação da cultura e da arte por saltos ou mutações", são, em certa medida, evitadas pelos historiadores da arte quase como um problema inconveniente. Expõe assim seu ponto de vista pessoal

De minha parte, defendo que a história demonstra uma razão no caminho percorrido, parece-me ser racional a relação entre o que houve no passado e o que acontece no presente, contudo, se percebo uma relação lógica entre presente e passado, não vejo assegurada essa relação para o futuro. Embora não tenhamos nenhuma garantia de saber o que vai acontecer no futuro baseado no que sabemos do passado, de vincularmos de forma lógica ou racional, o passado ao presente, isso não significa que o futuro, o desdobramento do que está acontecendo agora, não pode ser examinado como uma "evolução", como "uma relação", uma "forma lógica", isto é, pertencendo a uma "relação racional" face ao passado. O futuro ou o novo, não é uma decorrência linear ou lógica do presente, de alguma forma há uma subversão do existente e esse é o problema com que temos que nos confrontar. Se sentimos uma afinidade entre o presente e o passado é preciso indagar se existe uma relação causal entre o que aconteceu e o que agora está acontecendo. Se o que ocorre hoje é resultado cumulativo de inúmeras variáveis, ou se houve um salto do passado para o presente sem nenhuma relação lógica com aquilo que estava ocorrendo. 45

Com relação ao desenvolvimento da arte no tempo, Cipiniuk lança mão da metáfora dos movimentos dos cavalos no xadrez usada pelo antropólogo Claude Lévi-Strauss (1908-2009) para ilustrar como concebia a ideia de progresso da humanidade em "Raça e História". Ao invés de um desenvolvimento escalonado, ascendente e linear, semelhante ao movimento de uma pessoa subindo escadas; o progresso ocorreria tal como os movimentos em "L" do cavalo no xadrez: com várias possibilidades de progressões à disposição, desenha movimentos complexos, de idas, vindas e saltos. Em suas palavras

Talvez os fenômenos da arte e da cultura não sigam para mais longe na mesma direção, talvez modifiquem a sua trajetória, tal como Lévi-Strauss apontava, à maneira dos cavalos no jogo de xadrez, que possuem a sua disposição várias progressões, mas nunca no mesmo sentido. ${ }^{46}$

A reclamação de Cipiniuk revela a ausência de um debate continuado a respeito da definição do objeto artístico que oscila silenciosamente entre visões históricas Internalistas e Externalistas a partir do relato de uma situação vivenciada por ele como professor de história da arte na UERJ. Observa que essa ausência impacta estruturalmente as narrativas históricas que organizam e explicam o desenvolvimento artístico no tempo e se manifesta, por exemplo, na indefinição de um projeto curricular de formação acadêmica em história da arte. $\mathrm{O}$ autor

44 GELL, Alfred. A rede de Vogel, armadilhas como obras de arte e obras de arte como armadilhas. In: Arte \& Ensaios: Revista do Programa de Pós-Graduação em Artes Visuais. Tradução de Marcia Martins Campos e Laura Bedran. Rio de Janeiro: UFRJ, ano VIII, número 8, 2001. pp.174-191.

45 CIPINIUK, 2005, op. cit., p.3.

46 CIPINIUK, 2005, op. cit., p.3. 
esclarece que, ao contrário do que possa aparentar, seu desejo não é encerrar a discussão em uma "briga de comadres" departamental, mas defende que esse exemplo particular aponta para um silêncio mais amplo, dominante. Nas palavras de Cipiniuk, "Essa hesitação não é gratuita e despida de significado, ela esconde algo que se deseja evitar" 47 . Em suma, os argumentos de Cipiniuk convergem para um debate quase intocado, indesejado e, por isso, constantemente silenciado: a ideia de progresso na história da arte. Nos parece assim oportuno trazer para o centro do debate a tese proposta por Olga Hazan sobre como a ideia de progresso participa da construção da história da arte.

Em "O mito do progresso artístico: estudo crítico de um conceito fundador do discurso sobre arte desde o Renascimento", a historiadora da arte defende a tese de que a ideia de progresso não desempenha um papel secundário, uma função acessória na história da arte, mas dela tem participado de forma estrutural desde suas origens ${ }^{48}$. A autora afirma que a noção de progresso artístico é verificável "em todos os gêneros de escritos" (ou seja: "tanto nas obras generalistas como nos ensaios mais especializados"), "foi utilizada em todas as épocas" e "está associada à arte de todas as épocas" ${ }^{4}$. Evolução, progresso e decadência não são assim termos usados apenas por historiadores da arte do passado, ao contrário: "durante o século XX, enquanto a história da arte se desenvolveu a partir de um marco institucional, museal e universitário, a noção de progresso fundou as histórias da arte de todos os gêneros e os historiadores da arte continuam invocando essa noção nos vários tipos de trabalhos universitários" 50 .

Mesmo diante da presença e da importância do mito do progresso para a história da arte, cujo emprego não é verificado em contextos pontuais em que opera dado autor, mas faz parte das "normas que regem o conjunto do campo da história da arte", Hazan afirma que seu "uso permanente não deixou mais que rastros fugazes na historiografia crítica da arte" 51 . A autora elenca assim dois obstáculos que impedem uma análise aprofundada de tal fenômeno.

Em primeiro lugar, Hazan afirma que embora reconheça-se que a noção de progresso abranja quase todos os campos universitários, enquanto "outros ramos das ciências produziram inúmeros estudos críticos sobre tema", no caso específico da história da arte "o uso sistemático desta noção tem sido ignorado" 52 . O questionamento da autora revela assim certo lamento pela falta de referencial bibliográfico em quantidade proporcional à importância do tema, o que compromete o debate a respeito dele. Nas palavras de Hazan

Embora ainda continue a aparecer em domínios tão diversos como a biologia, a arqueologia, a antropologia, a história, a literatura, a psicologia, a filosofia, a teologia, a sociologia ou a economia, a noção de progresso hoje é colocada novamente em questão pela maioria das ciências humanas e sociais, com exceção da história da arte. [...] A noção de progresso [...] tem sido objeto de numerosas análises historiográficas em todas as disciplinas [...]. Na história da arte, ao contrário, esta questão só tem suscitado um interesse mínimo e a historiografia das obras dedicadas ao estudo da noção de progresso artístico, cujo uso é, no entanto, tão difundido, se limita a alguns escritos esporádicos. Este fenômeno merece ser questionado. ${ }^{53}$

${ }^{47}$ CIPINIUK, 2005, op. cit., p.4.

${ }^{48}$ HAZAN, Olga. El mito del progreso artístico: estudio crítico de un concepto fundador del discurso sobre el arte desde el Renacimiento. Tradução de Gabriel Menéndez Torrellas. 1ª ed. Madrid: Akal, 2010.

${ }^{49}$ HAZAN, 2010, op. cit., p.55.

${ }^{50}$ HAZAN, 2010, op. cit., p.51.

51 HAZAN, 2010, op. cit., p.23.

52 HAZAN, 2010, op. cit., p.18.

${ }^{53}$ HAZAN, 2010, op. cit., pp.36-37; 57. 
O segundo obstáculo apontado por Hazan é a impossibilidade de estabelecer uma cronologia para o seu uso e/ou aplicação pela história da arte da ideia de progresso ${ }^{54}$ : a simbiótica relação entre ambas é tão essencial à disciplina, quanto sutil, implícita, com limites tão bem camuflados que se tornam quase imperceptíveis. Mesmo os contornos mais identificáveis, revelam apenas a superfície do problema, não transparecendo seu papel estrutural. Por esse motivo, a autora não se contenta assim em investigar a presença da ideia de progresso na história da arte por meio do uso pessoal que cada autor dela faz na narrativa que constrói e propõe, isolando e particularizando sua ocorrência. Ao contrário, ao sustentar que os indícios apontam para o fato de que a ideia de progresso faz parte da "própria natureza do campo da história da arte" 55 , desempenhando um "papel estrutural", argumenta que a saída mais apropriada por ela encontrada para propor o estudo foi aborda-lo a partir de "uma perspectiva historiográfica do tema" 56 .

Hazan considera que, entre as ciências humanas, a história da arte seja a mais suscetível à ideia de progresso devido ao uso frequente de "critérios de avaliação estética ou comercial" associados ao "desenvolvimento da história" 57 . A pretensão de explicar o desenvolvimento artístico no tempo é acompanhada assim da necessidade de adoção de "juízos de valor" para "operar" e, depois, "legitimar" as "seleções que desembocam na configuração de uma história unilinear", que conduz quase que inevitavelmente ao uso de conceitos de "progresso e decadência" 58 . Como oportunamente recorda a autora, a história da arte sempre atuou em um território transdisciplinar, no qual se entrecruzam diversos campos de investigação científica, o que fez com que os historiadores da arte se sentissem, desde o início, "obrigados a estabelecer parâmetros" que pudessem "distingui-los de outros especialistas" 59 . Logo, a adoção de critérios de avaliação e de juízos de valores deve ser observada sob a ótica do processo de constituição, reconhecimento e institucionalização dessa jovem comunidade científica durante o século XIX, pois a necessidade dos historiadores da arte de integrar história da arte e juízo estético "dentro de uma estrutura cronológica centrada sobre a ideia de um desenvolvimento autônomo da arte" tem em vista a legitimação da disciplina. Por outro lado, Hazan não descarta a influência de fatores externos à relação entre história da arte e progresso: segundo ela, "essa disciplina sofreu um forte impacto de certas ideias tradicionalmente preconizadas em domínios filosóficos e científicos, como a ideia de uma razão histórica hegeliana ou de uma evolução fisiológica darwiniana" 60 .

Hazan propõe sua abordagem historiográfica do tema a partir de uma análise de manuais generalistas de história da arte e de estudos monográficos, especializadas em determinado recorte temático e/ou temporal. Para os fins do presente artigo, nos parece oportuno tratar particularmente das análises de Hazan a respeito de obras de perfil generalista. Segundo a historiadora da arte, a origem do interesse por grandes compêndios de história da arte deve ser entendida como uma demanda advinda com a criação das primeiras "cátedras universitárias de História da Arte na Europa e nos Estados Unidos" "61. Essas obras representam, "em grande medida, as tendências do final do século XIX, quando seus autores buscavam a todo custo racionalizar, uniformizar e apresentar de maneira 'científica' e objetiva uma história

\footnotetext{
${ }^{54}$ HAZAN, 2010, op. cit., p.18.

55 HAZAN, 2010, op. cit., p.56.

${ }^{56}$ HAZAN, 2010, op. cit., p.18.

57 HAZAN, 2010, op. cit., p.51.

${ }^{58}$ HAZAN, 2010, op. cit., p.97.

${ }^{59}$ HAZAN, 2010, op. cit., p.51.

${ }^{60}$ HAZAN, 2010, op. cit., p.344.

${ }^{61}$ HAZAN, 2010, op. cit., p.92.
} 
completa da arte" 62 , ao mesmo tempo em que também serviram para delimitar as particularidades da história da arte em relação aos campos que lhe eram conexos ${ }^{63}$. Assim, os compêndios de história da arte cumpriam (e, diga-se de passagem, ainda cumprem) dupla função. Por um lado, demarcavam o território em processo de conquista e ocupação, contribuindo para o reconhecimento das especificidades do objeto e dos métodos da jovem disciplina científica, evidenciando as leis internas que regiam as mudanças na história do desenvolvimento artístico por meio da construção de uma narrativa linear. De outro, foram também importantes instrumentos pedagógicos ao contribuir para a formação de discentes e docentes. Hazan chama atenção assim para o necessário processo formação de investigadores advindo de diversas áreas do conhecimento (geralmente, da filosofia, da antropologia, da arqueologia ou da conservação de museus) e que, ocupando os novos postos institucionais, "tiveram que reciclar-se rapidamente para estar em condições de divulgar o novo saber" ${ }^{\prime}$.

Com a aproximação da virada do século, além das obras históricas de caráter generalista, "se desenvolveu uma literatura monográfica mais teórica", entre as quais Hazan destaca os estudos de Aloïs Riegl e Heinrich Wölfflin, os quais "apresentaram a história da arte de acordo com as necessidades dessa jovem disciplina, ressaltando nela o caráter autônomo e objetivo, como para justificar sua presença no âmbito institucional" ${ }^{65}$. Hazan faz referência a duas obras em particular. Em ordem de publicação, a primeira é "Questões de estilo: fundamentos para uma história do ornamento" (1893) de Riegl; a segunda trata-se de "Conceitos fundamentais da história da arte: o problema da evolução dos estilos na arte mais recente" de Wölfflin, publicada pela primeira vez em 1915. Cada qual a seu modo, Riegl e Wölfflin tomaram para si a tarefa de construir e propor paradigmas para uma ciência da arte, empenhando-se em um exercício de demarcar os limites teóricos da jovem disciplina como um campo de investigação científica particular por meio da afirmação da forma e da visualidade como objeto último de análise da história da arte. Hazan destaca assim alguns aspectos centrais em ambas as obras, bem como a importância de ambos os autores no processo de reconhecimento da autonomia institucional da história da arte

Riegl e Wölfflin dedicaram-se a lançar um desenvolvimento estilístico autônomo (noção de Kunstwollen), que tivesse pouco a ver com o contexto da época, também apresentado de forma abstrata (conceito de Zeitgeist). Além de tentar separar a história da arte das várias disciplinas das quais provinha, indicando que apresentava uma evolução cronológica que respondia a uma lógica que lhe era própria, os autores destes ensaios mais teóricos tinham de fornecer métodos para esta disciplina que consideravam autônoma. Estes métodos deviam servir simultaneamente para analisar as obras e identificar meios de classificá-las, umas em relação a outras, em função de um plano histórico. Inseridos neste sistema no qual a classificação adquiriu uma importância desproporcional, atribuiu-se às obras uma função de reflexo em relação à evolução cronológica e estilística da arte. A articulação dos cinco princípios de Wölfflin, a ideia de que nem tudo é possível em todos os momentos, ou mesmo a ideia de Kunstwollen de Riegl, por meio da qual se desenvolvem os estilos de diferentes povos, constituíram as balizas que levaram inevitavelmente a estas generalizações. ${ }^{66}$

\footnotetext{
62 HAZAN, 2010, op. cit., p.81.

${ }^{63}$ HAZAN, 2010, op. cit., p.79.

${ }^{64}$ HAZAN, 2010, op. cit., p.93.

${ }^{65}$ HAZAN, 2010, op. cit., p.94.

${ }^{66}$ HAZAN, 2010, op. cit., p.94.
} 
O empenho em constituir uma ciência da arte tem relação com o esforço em todas as áreas do conhecimento, entre o século XIX e o início do século XX, de instituir pressupostos teóricos e métodos de investigação para um exercício de ciência que pretendia compreender toda a verdade a partir de modelos objetivos e universais. No caso da história da arte, foi de extrema importância o desenvolvimento dos chamados métodos formalistas. Um outro caso que pode ajudar a elucidar o que ocorria no âmbito da investigação científica dos objetos artísticos é o caso da Linguística.

Até o século XIX, tal como a arte, os estudos linguísticos se baseavam no estudo diacrônico e comparativo das línguas. É com o linguista suíço Ferdinand de Saussure (18571913) que a língua (e não a história das línguas) se torna objeto de estudo da Linguística: "a Linguística tem por único e verdadeiro objeto a língua considerada em si mesma e por si mesma" ${ }^{67}$. A perspectiva sincrônica, ou seja, aquela que estuda o fenômeno língua em contexto e se opõe de forma crítica à compreensão das línguas em uma escala evolutiva, como se o desenvolvimento de uma revelasse o caráter primitivo de outra. Percebe-se assim a estreita relação com um movimento ocorrido também na história da arte de dar atenção às formas consideradas decadentes.

A tendência a analisar o fenômeno artístico a partir dos elementos ligados à pura visualidade se colocava como uma tentativa de criar pressupostos de avaliação mais neutros. Como consequência dessa nova forma de olhar os fenômenos artísticos, segundo Baungarten, uma das mudanças de paradigma ocorridos nas últimas décadas do século XIX, da qual participou a Escola de Viena de História da Arte, é a ruptura com “a distinção entre o ‘bonito’ e o 'feio' no sentido de juízo valorativo dependente de critérios estéticos subjetivos. Como efeito dessa ruptura houve uma extensão do campo de pesquisa, tornando o interesse da história da arte mais abrangente" 68 . É importante ter em vista que o fenômeno artístico participa do território interdisciplinar da linguagem, logo é muito mais difícil propor pressupostos teóricos e métodos de investigação autônomos. Nesse sentido, é possível compreender o motivo de o esforço por criar métodos de análise objetiva na Linguística foi mais bem-sucedido do que no campo da investigação artística, justamente por essa questão da natureza do objeto.

Retomando o argumento de Hazan, apesar de defender que as "dificuldades de ordem metodológica" são correlatas tanto à escrita de compêndios generalistas (que pretendem apresentar um plano geral da produção reconhecida como artística) ou aos estudos monográficos (que colocam em evidência um determinado recorte, um enquadramento mais próximo de determinado contexto ou objeto), admite que elas são ainda mais evidentes nos manuais de caráter generalista. Nas palavras da autora

As obras de caráter generalista, enquanto manuais concebidos para uma
clientela universitária, se dirigem geralmente a adeptos recém iniciados,
àqueles que pretendem conhecer a história do mundo da arte. Por causa
deste programa vasto e ambicioso, pelo qual os autores não podem fazer
outra coisa a não ser abordar cada uma das épocas, cada assunto, cada
artista e cada obra superficialmente, a obra de caráter generalista se
converte na ilustração perfeita de todos os tipos de dificuldades
metodológicas que são mais difíceis de delimitar nos ensaios
especializados da disciplina. [...] A obra de caráter generalista ilustra o
paradoxo de uma disciplina inicialmente reservada a uma elite e que, ao
democratizar-se, tende a interessar um público amplo de leitores-
consumidores. A esta nova clientela, as obras deste tipo prometem
oferecer saber e prazer por meio de monumentos que são apresentados

${ }^{67}$ SAUSSURE, Ferdinand de. Curso de linguistica geral. Tradução de Antônio Chelini, José Paulo Paes e Izidoro Blikstein. $28^{a}$ edição. São Paulo: Cultrix, 2012. p.305.

${ }^{68}$ BAUMGARTEN, 2008, op. cit., p.23. 
como reflexos dos marcos de sua própria história. Melhor que todo gênero de escrito sobre arte, a obra de perfil generalista lança luz sobre os numerosos problemas decorrentes desse paradoxo e que podemos resumir da seguinte forma: estas obras agrupam histórias locais para compor uma história universal; apresentam problemas de periodização e de nomenclatura; antes de estabelecer conexões entre as obras de arte e seu contexto histórico, traçam frequentemente causalidades precipitadas em forma de crise e progresso; por último, abusam do conceito de estilo para ilustrar estas esquematizações. ${ }^{69}$

Hazan acentua os dois problemas de método que, do seu ponto de vista, "adquirem uma importância singular" e estão intimamente relacionados. O primeiro é o fato de obras de caráter generalista associarem "múltiplas épocas e lugares entre si”. O outro envolve o processo de eleição das produções que constituirão tais narrativas ${ }^{70}$. Esses "problemas de periodização e definição" levam os "historiadores da arte a edificar uma história universal composta de uma superposição de histórias regionais" e, ao mesmo tempo, justificar o "sistema de valores" ("estéticos e de mercado, subjetivos e flutuantes") adotados, os balizadores usados no processo de seleção inerente à construção de tal história. Somente lhes resta "adotar juízos qualitativos em relação aos artistas, às obras ou aos períodos estudados"71. E é justamente nesse ponto nevrálgico que o uso de conceitos como progresso e decadência se mostra oportuno

Para construir uma "história da arte", eles [os historiadores da arte] tendem a eliminar um bom número de artistas e são assim obrigados a justificar e colocar em evidência sua seleção, enfatizando as características e talentos dos artistas escolhidos [...]. A necessidade de operar e depois legitimar essas eleições faz com que se encontrem automaticamente reunidas as duas condições suficientes para a utilização dos conceitos de progresso e decadência. Na verdade, basta que um autor simplesmente apresente a história de maneira esquemática, linear, emitindo juízos sobre as obras, os artistas, os períodos e as culturas, para que automaticamente sua história faça uso de progressos e decadências. ${ }^{72}$

A historiadora da arte chega a usar como metáfora a imagem de uma infecção viral: seja nomeada como "estilo", "civilização", "evolução" ou "progresso", uma "entidade tangível" atravessa "tempos e lugares simultaneamente, [...] se introduz e se propaga para mais tarde debilitar-se, abdicar e desaparecer, vencida por um novo vírus que a substitui”73.

Hazan avalia ainda que desde a "primeira literatura artística" até a reivindicação do caráter científico disciplinar e da inclusão da história da arte na estrutura universitária de forma mais autônoma, "o discurso sobre a arte tem mostrado regularmente o desenvolvimento da arte de modo racional e o objeto de estudo selecionado provido de qualidades" "74. A partir dessas reflexões, é possível concluir que a história da arte sempre se esforçou em naturalizar a marcha do progresso e seus movimentos de ascensão e declínio, atribuindo-lhe uma neutralidade inconciliável com a subjetividade e a relatividade dos critérios de seleção e análise. Nesse sentido, vale citar alguns comentários que Hans Belting tece sobre essa história da arte norteada por uma

${ }^{69}$ HAZAN, 2010, op. cit., pp.96-97.

${ }^{70}$ HAZAN, 2010, op. cit., p.97.

${ }^{71}$ HAZAN, 2010, op. cit., p.51.

72 HAZAN, 2010, op. cit., pp.51-52.

${ }^{73}$ HAZAN, 2010, op. cit., p.97.

${ }^{74}$ HAZAN, 2010, op. cit., p.52. 
vontade da forma e que pretende basear-se numa suposta pureza visual e, de certa forma, de método. Em suas palavras, "estilo seria aquele atributo da arte para o qual se queria demonstrar uma história ou um desenvolvimento em conformidade com a lei" 75 . Criado como forma de evidenciar o território restrito à história da arte, qualquer outro conteúdo que parecesse supérfluo à forma era rebaixado. Por exemplo

\begin{abstract}
Nos textos de ciência da arte [...] o biográfico e o anedótico é sacrificado pelas "leis do estilo" e pelas "transformações da forma". O saber histórico adquirido no século XIX parece subitamente supérfluo, pois se aprendeu a ler a história da arte a partir das próprias formas. Os artistas e sua vida fornecem quando muito informações que fazem parte da história estilística, mas não constituem mais os temas. Nessa modalidade, o "estilo" também é um polo oposto do indivíduo e uma garantia da visão pura que se encontra em todos os homens e não parece ligada a nenhum saber cultural prévio. [...] Curiosamente, mesmo essa ciência da forma tornou-se, mais uma vez, um lugar de identidade [...] ${ }^{76}$
\end{abstract}

Mesmo diante do esforço em autocentrar-se, Belting lembra que "a história escrita da arte não nasceu em um espaço apartado da ciência pura”. Logo, mesmo a abordagem formalista não respondia somente a uma espécie de "desenvolvimento interno de sua própria especialidade, mas repercutia a discussão do seu presente, ainda que de maneira muito indireta e contraditória”. Assim, seja nas obras de caráter generalista ou no esforço em criar uma forma universal de análise das formas artísticas, a história da arte "estava fixada, na primeira modernidade, sempre na imagem abstrata de uma história da arte que segue o curso natural’77.

Tendo em vista que a modernidade europeia é fundamentada em ideias como universalismo e progresso, é perceptível que a história de arte que se pretende neutra é um lugar de identidade. Outro exemplo é a própria invenção da ideia de arte. Segundo Belting, "a arte foi sabidamente uma ideia da época do Iluminismo, que nela reconhecia uma validade atemporal e universal, para além de todas as diferenças entre os produtos artísticos individuais: atemporal e universal como os direitos humanos mesmos, que afinal deviam ser válidos para todos os homens individualmente tão diferentes" ${ }^{\text {78 }}$

Voltando a Hazan, a historiadora da arte afirma ainda que a noção de progresso artístico pode se apresentar de cinco formas diferentes

a) a ideia de transformação, entre duas eras numa entidade tangível e homogênea que chamamos de "estilo"; b) a ideia de que esta transformação opera de forma unidirecional e pré-determinada; c) a ideia de uma riqueza de conhecimentos técnicos e teóricos, que cada geração acrescentaria a essência de suas características próprias; d) a ideia de uma mudança qualitativa associada a este processo, segunda a qual cada geração de artistas é considerada limitada por problemas que não serão resolvidos até a próxima geração; e) por último, a ideia de que podemos avaliar essas transformações em termos de lucros e perdas, de acordo com o critério "objetivo", absoluto e normativo descrito anteriormente. Este critério se constrói invariavelmente, ao menos no que concerne às obras produzidas

75 BELTING, 2006, op. cit., p.41.

${ }^{76}$ BELTING, 2006, op. cit., p.48.

77 BELTING, 2006, op. cit., pp.49-50.

${ }^{78}$ BELTING, 2006, op. cit., p.144. 
antes do século XIX, usando uma dosagem variável de mimese e do ideal antigo, clássico, antropométrico e ocidental. ${ }^{79}$

Entre as contradições encerradas em uma história da arte generalista, Hazan aponta a “ambição de querer conjugar as manifestações artesanais e depois artísticas (a partir do Renascimento) de diversos tempos e lugares”. O aumento no número de reinvindicações pela inclusão de tantos outros objetos (feitos com a intenção ou não de ser arte) à grande história da arte demanda novos métodos de investigação. Ao querer incluir "todas as formas de arte, de todas as épocas e todos os países", na tentativa de se criar uma narrativa completa e ampla o suficiente, tem-se como resultado uma história "mais redutora", a qual "submete todas as tradições para um único, universal e desenvolvimento progressivo da arte". Como exemplo, Hazan cita o fato de que à "corrente principal, geralmente ocidental, são incorporadas circunstancialmente ramificações 'não-ocidentais", que são reagrupadas e designadas "de forma negativa" ". Mesmo considerando legítima a aspiração dos autores das "obras modernas de caráter generalista" de oferecerem "uma história da arte completa e exaustiva que compreenderia o maior número possível de formas de arte, de épocas e de culturas", que pudesse dar conta da diversidade da produção artística, bem como a revisão da estrutura dos manuais de história da arte geral na tentativa de amplia-los e melhorá-los; Hazan avalia que essas mutações (propostas e experimentadas nas últimas décadas do século XX) "entram em contradição com a estrutura linear" e são incompatíveis com a antiga "estrutura cronológica", "derivada da ideia de um desenvolvimento unilateral e universal da arte".

Hazan é então bastante taxativa: "sob estas condições, não é certo que a obra de caráter generalista possa sobreviver às exigências impostas sobre as novas tendências na disciplina de história da arte" 81 . Considerando o papel pedagógico de tais manuais, Hazan complementa assim seu argumento

Com efeito, parece difícil conceber que uma obra de dimensões razoáveis possa incluir os desenvolvimentos completos das diversas formas de arte de um grande número de culturas; e é igualmente ilusório imaginar que os estudantes estejam em condições de assimilar toda essa informação em um curso de três ou seis créditos. A menos que se associe a obra de caráter generalista a programas informatizados que permitam o armazenamento de um número ilimitado de informações, processo que implica em renunciar a ordem cronológica unilateral e restritivo, não será jamais possível oferecer à clientela universitária uma história da arte total que inclua e conjugue as histórias completas de cada um dos países que, nas edições atuais, são evocados unicamente em referência a certas épocas. Esta história deveria, idealmente falando, não somente ter em conta os desenvolvimentos artísticos de países tão diversos como Mesopotâmia, Egito, Japão ou Grécia, durante um período que se estende desde a Préhistória até os dias de hoje, mas deveria também estabelecer relações entre estas diferentes culturas para justificar o que ainda se apresenta como o desenvolvimento homogêneo da civilização ocidental. Como, por outro lado, a obra de caráter generalista de hoje responde essencialmente às necessidades pontuais de uma clientela de estudantes em formação, a síntese continua em rigor e não permite a exaustividade que exigem as novas tendências de nossa disciplina. ${ }^{82}$

${ }^{79}$ HAZAN, 2010, op. cit., p.52.

${ }^{80}$ HAZAN, 2010, op. cit., p.80.

${ }^{81}$ HAZAN, 2010, op. cit., pp.91-92.

82 HAZAN, 2010, op. cit., p.92. 
Entre as novas tendências da disciplina, está o fato de que se, em sua origem, a disciplina foi marcada por um caráter exclusivo, sua popularização posterior prevê as reclamações por representatividade da parte daqueles que não se veem contemplados pelas antigas narrativas generalistas. Tendo em vista que a identidade do leitor dessas obras “já não é exclusivamente masculino, branco e ocidental", os novos públicos parecem "não querer contentar-se mais com os esquemas sobre os quais se havia edificado a disciplina"83.

Se mulher, feminista, minoria racial e étnica ou homossexual, essa clientela reage diante daquilo que percebe como a sua própria exclusão. As reivindicações advindas da "correção política" fazem com que, nos dias de hoje, cada leitor exija ver-se representado individualmente na obra de caráter generalista, pois é através de um movimento ao mesmo tempo libertador e reacionário que buscamos hoje, em nome da identificação e da autorreferência, abrir as portas à diversidade. ${ }^{84}$

A obra de caráter generalista "lança luz sobre os numerosos problemas" emergentes da incapacidade da narrativa geral e, ao mesmo tempo, muito bem delineada geopoliticamente em lidar com as particularidades de um outro inicialmente por ela não contemplado. Sendo "uma disciplina inicialmente reservada a uma elite e que, ao democratizar-se, passa a interessar um público mais amplo de leitores-consumidores", o paradoxo está justamente nesta abertura do campo $^{85}$.

A historiadora da arte Nicole Dubreuil, que é professora da Universidade de Montreal, instituição na qual Olga Hazan também atua, em prefácio que escreve para a obra de Hazan, salienta dois aspectos que também consideramos essenciais para pensar sua tese. Em primeiro lugar, argumenta que a reflexão crítica empreendida pela autora faz parte de uma historiografia atual que questiona as narrativas históricas da arte. Em segundo lugar, e por consequência, não deixa de ser óbvio que o instigador do discurso de progresso, o qual "anima a grande história do museu e a história da arte”, é branco, macho e europeu, ou seja, o contrário de Olga Hazan mulher originária do Oriente Médio. Para Dubreuil esses dados biográficos tornam compreensíveis a não adoção pela autora do "ponto de vista das histórias gerais de arte". Hazan catalisa o questionamento das grandes narrativas por todos os reprimidos pela tradição: as mulheres, os não-ocidentais, os colonizados, as minorias, os excluídos. Em suma: todos os que reclamam seu lugar na narrativa histórica da arte. No entanto, é justamente em detalhes desses dois aspectos que reside o ponto de virada da obra de Hazan. Como observa Dubreuil, "a linha do progresso corre o risco de reaparecer, associada, por exemplo, ao nível de consciência das relações sociais ou das relações de gênero, um exercício em que as representações da arte, por uma espécie de movimento pendular, são frequentemente avaliadas e condenadas a ocupar as posições mais reacionárias" 86 .

Diante de tão densa análise sobre a função estrutural da ideia de progresso na história da arte, que revela também parte da identidade cultural europeia que caracteriza a disciplina e de um amplo debate que pretende revisar as narrativas mestras ocidentais e os métodos de análise da disciplina, nós - historiadores da arte do presente - somos muitas vezes tentados a adotar uma postura de resistência diante de ideias como progresso e universalismo, por exemplo, como se fossem aspectos que precisassem ser superados. Essa soberba nos faz cair nas mesmas e velhas

${ }^{83}$ HAZAN, 2010, op. cit., p.95.

${ }^{84}$ HAZAN, 2010, op. cit., p.95.

${ }^{85}$ HAZAN, 2010, op. cit., pp.96-97.

86 DUBREUIL in: HAZAN, 2010, op. cit., pp.5-9. 
armadilhas, como se ocupássemos um ponto de vista privilegiado no desenvolvimento temporal. Nesse sentido, nos parece que o mérito da obra de Hazan não é tanto apontar os problemas e indicar tão somente as limitações dos modelos narrativos sob os quais a história da arte se instituiu ou de romper definitivamente com a ideia de progresso, mas que os historiadores se tornem mais conscientes das implicações do uso indiscriminado de determinadas categorias (como estilo) ou de substituir um progresso por outro, como bem evidenciou Dubreuil. 